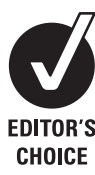

${ }^{1}$ School of Public Health and Family Medicine, University of Cape Town, Cape Town, South Africa; ${ }^{2}$ Department of Epidemiology, Mailman School of Public Health, Columbia University, New York, USA; ${ }^{3}$ MRC Stress and Anxiety Disorders Unit, Department of Psychiatry, University of Stellenbosch, Tygerberg, South Africa; ${ }^{4}$ Department of Psychiatry and Mental Health, University of Cape Town, Cape Town, South Africa; ${ }^{5}$ University of the Witwatersrand, Johannesburg, South Africa;

${ }^{6}$ Department of Society, Human Development and Health,

Harvard School of Public Health, Boston, USA

Correspondence to: Professor L Myer, School of Public Health and Family Medicine, University of Cape Town, Anzio Road, Observatory 7925, Cape Town, South Africa; landon.myer@uct.ac.za

Accepted 21 November 2008 Published Online First 15 December 2008

\title{
The mental health impact of AIDS-related mortality in South Africa: a national study
}

\author{
L Myer, ${ }^{1,2}$ S Seedat, ${ }^{3}$ D J Stein, ${ }^{3,4}$ H Moomal, ${ }^{5}$ D R Williams ${ }^{6}$
}

\author{
ABSTRACT \\ Background: Few data exist on how the HIV/AIDS \\ epidemic may influence population mental health. The \\ associations were examined between knowing someone \\ who died of HIV/AIDS and common mental disorders \\ among South African adults.
}

Methods: Between 2002 and 2004, a nationally representative sample of 4351 adults were interviewed about personally knowing someone who died of HIV/AIDS, and the World Health Organization Composite International Diagnostic Interview was used to generate psychiatric diagnoses for depression, anxiety and substance abuse disorders during the preceding 12 months based on the Diagnostic and Statistical Manual, 4th edition (DSM-IV).

Results: Overall, $42.2 \%$ of the sample knew someone who died of HIV/AIDS, and $16.5 \%$ met the criteria for at least one DSM-IV diagnosis. Individuals who knew someone who died of HIV/AIDS were significantly more likely to have any DSM-IV defined disorder, including any depressive, anxiety or substance-related disorder $(\mathrm{p}<0.001$ for all associations). In multivariate models adjusted for participant demographic characteristics, life events and socioeconomic status, individual disorders significantly associated with knowing someone who died of HIV/AIDS included generalised anxiety disorder, social phobia and alcohol/drug dependence or abuse. Based on these results, it is estimated that up to $15 \%$ of 12 -month DSM-IV disorders in the South African adult population may be related to knowing someone who died of HIV/AIDS.

Conclusion: These novel data suggest that AIDS-related mortality may contribute substantially to the burden of mental disorders in settings of high HIV prevalence. While this finding requires further investigation, these data suggest the need to strengthen mental health services in communities where HIV/AIDS is prevalent.

HIV/AIDS is one of the leading causes of morbidity and mortality in developing countries, particularly in sub-Saharan Africa. ${ }^{1}$ In South Africa, an estimated 5 million individuals are infected, and HIV/AIDS is the leading cause of death nationally. ${ }^{2}$ The extent of the epidemic and its associated mortality, the sexual transmission of the virus and the absence of a cure have led to the widespread stigmatisation of HIV/AIDS in South Africa and many other countries. ${ }^{3}$

With growing attention to the burden of disease associated with mental disorders in low- and middle-income countries, ${ }^{4}$ the potential interactions between the HIV/AIDS epidemic and mental health require urgent attention. ${ }^{5}{ }^{6}$ There has been considerable research attention to how different mental disorders shape risk-taking behaviours that predispose to HIV acquisition, ${ }^{7}$ suggesting in turn that population mental health may contribute to the spread of HIV through communities. ${ }^{8}$ The mental health impact of HIV infection on individuals is also well documented. One systematic review found that major depression was twice as prevalent in HIV-infected compared with HIVuninfected individuals, ${ }^{9}$ and individual studies have demonstrated that anxiety and substance abuse disorders are also more common among individuals living with HIV/AIDS. ${ }^{10-12}$ In addition, recent findings suggest that the progression of HIV disease may interact with mental health over time, via ongoing psychological distress, central nervous system infection or impaired retention in care or adherence to treatment. ${ }^{13-15}$

However, there is still little understanding of how the HIV/AIDS epidemic may impact indirectly on population mental health. It is possible that specific aspects of the HIV/AIDS epidemic, such as fear of HIV infection or knowing individuals who are infected with the virus, may serve as a stressor with negative effects on mental health, even among those who are not themselves infected. This is particularly plausible in settings where HIV is both prevalent and highly stigmatised, as in many parts of sub-Saharan Africa. Here, AIDS-related mortality is most common among individuals of reproductive age (a segment of the population that is otherwise relatively healthy); in turn, AIDS-related deaths in many communities may represent a particularly profound life event that may contribute to the aetiology of common mental disorders.

Few studies have examined the potential impact of HIV-related mortality on population mental health. Most work from sub-Saharan Africa related to this issue has focused on the mental health of children orphaned following the deaths of their parents from HIV/AIDS, showing increased depression and suicidality among orphans. ${ }^{16}{ }^{17}$ Other studies have focused on the mental health of healthcare workers and other caregivers of HIVinfected individuals, demonstrating that this specific group is particularly likely to suffer negative psychosocial consequences of caring for patients with a highly stigmatised chronic disease. ${ }^{18} 19$ However, to date, there has been no research into this question in general population samples. Using a nationally representative survey, we examined the associations between knowing someone who died of HIV/AIDS and common mental disorders during the preceding 12 months among South African adults.

\section{METHODS}

Data come from the South African Stress and Health Study, a national survey of mental health 
conducted between January 2002 and June 2004 as part of the World Mental Health Initiative. The study rationale and methods have been detailed previously. ${ }^{20}$ Briefly, a probability sample of South African adults was selected using a three-stage design. Census units were stratified according to province, urban or rural location and majority population group (African, coloured, white or Indian); 960 units were selected from the resulting strata, with the number proportional to size. Within each enumerator area, a random sample of five households was selected. Within each household, a single adult was selected at random. The overall response rate for the study was $85.5 \%$, and the final sample size was 4351 individuals. Interviews were conducted by fieldworkers with special training in psychiatric interviewing, working in one of six local languages. Interviews lasted approximately 3 hours and sometimes took place over multiple home visits. Participant demographic characteristics and measures of socioeconomic status were collected using standard questionnaire items.

Data on knowledge of someone who died of HIV/AIDS comes from the item, "Have you ever known anyone personally who has died of HIV or the AIDS virus?"; responses were coded as yes or no. Mental disorders were measured using the Composite International Diagnostic Interview (CIDI), version 3.0. ${ }^{21}$ This fully structured interview guide is designed to be administered by lay interviewers to derive diagnoses based on the Diagnostic and Statistical Manual, 4th edition (DSM-IV). The CIDI has demonstrated high levels of inter-rater and test-retest reliability ${ }^{22}$ and has been validated against clinical assessment. ${ }^{23}$ The English CIDI was translated into six other major languages used in South Africa, with iterative back-translation by panels of bilingual experts, following World Health Organization (WHO) recommendations; discrepancies were resolved by an expert panel. This analysis includes only 12 -month anxiety (agoraphobia, generalised anxiety disorder, social phobia, panic disorder and post-traumatic stress disorder), depressive (major and minor depression) and substance-related (alcohol dependence or abuse and drug dependence or abuse) disorders. The overall prevalence and demographic correlates of 12-month DSM-IV disorders has been reported previously. ${ }^{24}$

The Kessler K-10 scale was used to measure global psychological distress, including significant pathology which does not meet formal criteria for a psychiatric illness. ${ }^{25}{ }^{26}$ This scale measures the following symptoms over the preceding 30 days by asking: "In the past 30 days, how often did you feel: nervous; so nervous that nothing could calm you down; hopeless; restless or fidgety; so restless that you could not sit still; depressed; that everything was an effort; so sad that nothing could cheer you up; worthless; tired out for no good reason?" The frequency with which each of these items was experienced was recorded using a 5-point Likert scale ranging from "none of the time" to "all the time". This score was then summed, with increasing scores reflecting an increasing degree of psychological distress; in analysis, we examined the K-10 scale using ordinal categories for low, moderate, high and very high psychological distress (scores of 10-19, 20-24, 25-29 and $\geqslant 30$ respectively) and as a binary variable comparing scores of $0-29$ vs $\geqslant 30$.

Lifetime experience of trauma was measured through 28 items used to screen for post-traumatic stress disorder in the World Mental Health Survey, including experiences of accidents, illness, loss of loved ones, abuse, crime, war and natural disasters at any time. The Life Event schedule of the World Mental Health Survey was used to measure life events occurring in the previous 12 months based on whether the participant had experienced: (1) illness or injury; (2) physical attack; (3) robbery; (4) death of someone close; (5) separation from spouse or partner; (6) end of another close relationship; (7) being fired from a job; (8) retiring from a job against the participant's will; (9) losing a job for another reason; (10) searching for employment without success for over a month; (11) major financial crisis; (12) problems with the police; or (13) whether someone close to the participant had experienced illness, injury or physical attack. Recent and traumatic life events were categorised into ordinal variables of none, $1-2,3-4$ and 5 or more life events.

Data were analysed using Stata, version 9.2 (Stata Corporation, College Station, TX, USA). All analyses included person-level weights that incorporated sample selection, nonresponse and post-stratification factors. Pearson's chi-squared tests were used to examine crude associations between knowing someone who died of HIV/AIDS and participant demographic characteristics, socioeconomic status, life events and mental disorders. All statistical tests are two-sided at $\alpha=0.05$. We developed a series of multiple logistic regression models to examine the association between different mental disorders and knowing someone who died of HIV/AIDS after adjustment for the possible confounding influence of participant demographic characteristics (including socioeconomic status), HIV testing history and recent and lifetime traumatic life events. The coefficients from these models are reported as odds ratios (OR) with $95 \%$ confidence intervals (CI). The proportion of mental disorders attributable to knowing someone who died of HIV/ AIDS among the adult population of South Africa (populationattributable fraction) was estimated using $\left[p^{*}(\mathrm{OR}-1)\right] /$ $\left[p^{*}(\mathrm{OR}-1)+1\right]$, where $p$ is the proportion of individuals in the population who know someone who died of HIV/AIDS. All population-attributable fraction calculations used odds ratios from fully adjusted regression models.

\section{RESULTS}

Of the 4351 individuals interviewed, 4182 (96\%) had data available on whether they personally knew someone who died of HIV/AIDS, and are included in this analysis; there were no significant differences between those included and the 169 participants excluded from this analysis (data not shown).

The mean age in the sample was 36.9 years and $77 \%$ were black (table 1). Overall, $42.2 \%$ of the sample knew someone who died of HIV/AIDS (95\% CI $40.0 \%$ to $44.4 \%$ ). Knowing someone who died of HIV was strongly associated with younger age, living in an urban area and black race $(p<0.001$ for all associations). Increasing levels of education and household ownership of assets were both associated with knowing someone who died of HIV/AIDS, although household income level and individual employment status showed no association. Overall, $22 \%$ of participants reported that they had been tested for HIV, and the vast majority of these (99\%) had last been tested in the previous 12 months. A previous HIV test was strongly associated with knowing someone who died of HIV/ AIDS (27\% of individuals who knew someone who died of HIV/ AIDS had been tested previously, compared with $18 \%$ of those who did not know someone who died of HIV/AIDS; $p<0.001$ ).

There were strong dose-response relationships between knowing someone who died of HIV/AIDS and experience of both recent life events as well as any traumatic life events (table 1). In an analysis of individual types of life events (table 2), knowing someone who died of HIV/AIDS was strongly associated with the more general recent life event items corresponding to the death of someone very close to the 
Table 1 Description of participant demographic and socioeconomic characteristics, overall and by knowledge of someone who died of HIV/ AIDS

\begin{tabular}{|c|c|c|c|c|}
\hline & $\begin{array}{l}\text { Total } \\
\text { sample } \\
\text { (n=4182) }\end{array}$ & $\begin{array}{l}\text { Personally } \\
\text { knows } \\
\text { someone who } \\
\text { died of AIDS } \\
\text { (n=1743) }\end{array}$ & $\begin{array}{l}\text { Does not } \\
\text { personally } \\
\text { know someone } \\
\text { who died of } \\
\text { AIDS } \\
(n=2439)\end{array}$ & p Value \\
\hline $\begin{array}{l}\text { Personally knows } \\
\text { someone who died of } \\
\text { AIDS }\end{array}$ & 42.2 & & & \\
\hline \multicolumn{5}{|l|}{ Age (years) } \\
\hline 18-29 & 39.6 & 42.7 & 37.4 & $<0.001$ \\
\hline $30-39$ & 22.5 & 24.4 & 21.1 & \\
\hline $40-49$ & 17.8 & 18.4 & 17.4 & \\
\hline $50+$ & 20.3 & 14.5 & 24.2 & \\
\hline \multicolumn{5}{|l|}{ Sex } \\
\hline Male & 45.3 & 46.3 & 44.6 & 0.461 \\
\hline Female & 54.7 & 53.8 & 55.4 & \\
\hline \multicolumn{5}{|l|}{ Location } \\
\hline Rural & 38.8 & 33.0 & 43.1 & $<0.001$ \\
\hline Urban & 61.2 & 67.0 & 65.9 & \\
\hline \multicolumn{5}{|l|}{ Race } \\
\hline Black & 76.7 & 83.9 & 71.5 & $<0.001$ \\
\hline Coloured & 11.3 & 9.6 & 12.6 & \\
\hline White & 8.7 & 4.2 & 12.0 & \\
\hline Asian & 3.3 & 2.4 & 4.0 & \\
\hline \multicolumn{5}{|l|}{ Education } \\
\hline None & 6.7 & 4.9 & 8.1 & $<0.001$ \\
\hline Grade 1-7 & 19.7 & 16.4 & 22.0 & \\
\hline Grade 8-11 & 35.2 & 35.1 & 35.2 & \\
\hline $\begin{array}{l}\text { Completed high } \\
\text { school }\end{array}$ & 23.1 & 26.7 & 20.5 & \\
\hline $\begin{array}{l}\text { Post-high school } \\
\text { education }\end{array}$ & 15.3 & 16.9 & 14.2 & \\
\hline \multicolumn{5}{|l|}{ Currently employed } \\
\hline No & 68.9 & 69.3 & 68.7 & 0.757 \\
\hline Yes & 31.1 & 30.7 & 31.3 & \\
\hline \multicolumn{5}{|l|}{$\begin{array}{l}\text { Household income } \\
\text { (South African rand) }\end{array}$} \\
\hline 0 (none) & 13.6 & 12.7 & 14.2 & 0.226 \\
\hline $1-5000$ & 30.4 & 32.6 & 28.8 & \\
\hline $5001-25000$ & 15.7 & 14.7 & 16.4 & \\
\hline $25000-100000$ & 19.5 & 19.9 & 17.2 & \\
\hline $100001+$ & 20.8 & 20.0 & 21.4 & \\
\hline \multicolumn{5}{|l|}{$\begin{array}{l}\text { Assets owned by } \\
\text { household }\end{array}$} \\
\hline $0-5$ & 39.1 & 34.0 & 42.8 & $<0.001$ \\
\hline $6-12$ & 38.2 & 45.0 & 33.2 & \\
\hline $13-17$ & 22.7 & 21.0 & 23.9 & \\
\hline \multicolumn{5}{|l|}{ Ever tested for HIV } \\
\hline No & 78.5 & 73.2 & 82.5 & $<0.001$ \\
\hline Yes & 21.5 & 26.8 & 17.6 & \\
\hline \multicolumn{5}{|l|}{ Recent life events } \\
\hline None & 34.6 & 26.9 & 40.2 & $<0.001$ \\
\hline $1-2$ & 40.0 & 41.2 & 39.1 & \\
\hline $3-4$ & 17.6 & 21.3 & 14.9 & \\
\hline 5 or more & 7.9 & 10.7 & 5.8 & \\
\hline \multicolumn{5}{|l|}{ Traumatic life events } \\
\hline None & 26.9 & 20.9 & 31.2 & $<0.001$ \\
\hline $1-2$ & 49.7 & 49.4 & 49.9 & \\
\hline $3-4$ & 10.7 & 13.2 & 8.8 & \\
\hline 5 or more & 12.8 & 16.5 & 10.0 & \\
\hline
\end{tabular}

All cells are percentages (\%). participant, the participant having a serious illness or injury or someone very close to the participant having a very serious illness or injury. However, knowing someone who died of HIV/ AIDS was also strongly associated with a number of other life events that were unrelated to illness or death.

Overall, $16.5 \%$ of the study population met the criteria for at least one DSM-IV diagnosis in the previous 12 months, including $4.9 \%$ having any depressive disorder, $8.1 \%$ having any anxiety disorder and $5.8 \%$ having any substance use disorder. There were strong crude associations between knowing someone who died of HIV/AIDS and different mental disorders (table 3). Higher levels of non-specific psychological distress during the previous 30 days were reported by individuals who knew someone who died of HIV/AIDS $(9.9 \%$ of participants who knew someone who died of HIV/AIDS reported very high levels of psychological distress, compared with $7.4 \%$ of individuals who did not, $\mathrm{p}<0.001)$. Individuals who knew someone who died of HIV/AIDS were significantly more likely to have any DSM-IV defined disorder, including any depressive disorder, any anxiety disorder and any substancerelated disorder, during the previous 12 months $(p<0.001$ for all associations). Among specific conditions, knowing someone who died of HIV/AIDS was associated with major depressive disorder, agoraphobia, generalised anxiety disorder, social phobia, as well as alcohol and drug dependence or abuse. There were no associations between knowing someone who died of HIV/AIDS and panic disorder or post-traumatic stress disorder.

Table 4 shows the results of multiple logistic regression modelling to examine the association between knowing someone who died of HIV/AIDS and different mental disorders.

Table 2 Crude associations between recent life events and knowing someone who died of HIV/AIDS

\begin{tabular}{|c|c|c|c|c|}
\hline & $\begin{array}{l}\text { Total } \\
\text { sample } \\
\text { ( } n=4182 \text { ) }\end{array}$ & $\begin{array}{l}\text { Personally } \\
\text { knows } \\
\text { someone who } \\
\text { died of AIDS } \\
(\mathrm{n}=1743)\end{array}$ & $\begin{array}{l}\text { Does not } \\
\text { personally know } \\
\text { someone who } \\
\text { died of AIDS } \\
\text { ( } n=2439)\end{array}$ & p Value \\
\hline $\begin{array}{l}\text { Death of someone } \\
\text { close to you }\end{array}$ & 27.8 & 32.6 & 24.3 & $<0.001$ \\
\hline $\begin{array}{l}\text { You having a serious } \\
\text { illness or injury }\end{array}$ & 12.0 & 13.8 & 10.6 & 0.004 \\
\hline $\begin{array}{l}\text { Someone close to you } \\
\text { having a serious } \\
\text { illness, injury, } \\
\text { physical attack or }\end{array}$ & 13.8 & 17.6 & 10.9 & $<0.001$ \\
\hline $\begin{array}{l}\text { Being a victim of a } \\
\text { serious physical } \\
\text { attack or assault }\end{array}$ & 6.1 & 7.6 & 5.1 & 0.018 \\
\hline $\begin{array}{l}\text { Being robbed or } \\
\text { having home burgled }\end{array}$ & 11.5 & 13.1 & 10.3 & 0.046 \\
\hline $\begin{array}{l}\text { Separation due to } \\
\text { marital difficulties }\end{array}$ & 5.3 & 5.7 & 5.0 & 0.335 \\
\hline $\begin{array}{l}\text { Break up of a close } \\
\text { relationship }\end{array}$ & 10.8 & 14.9 & 7.9 & $<0.001$ \\
\hline Fired from job & 4.1 & 4.8 & 3.6 & 0.145 \\
\hline $\begin{array}{l}\text { Retiring when did not } \\
\text { want to }\end{array}$ & 4.0 & 4.6 & 3.5 & 0.234 \\
\hline $\begin{array}{l}\text { Losing job for another } \\
\text { reason }\end{array}$ & 6.9 & 8.2 & 6.0 & 0.052 \\
\hline $\begin{array}{l}\text { Unsuccessfully } \\
\text { searching for a job }\end{array}$ & 15.0 & 18.8 & 12.2 & $<0.001$ \\
\hline Major financial crisis & 35.4 & 40.1 & 32.0 & $<0.001$ \\
\hline $\begin{array}{l}\text { Problems with the } \\
\text { police }\end{array}$ & 4.3 & 6.2 & 2.9 & $<0.001$ \\
\hline
\end{tabular}

All cells are percentages $(\%)$. 
Table 3 Crude associations between mental disorders and knowing someone who died of HIV/AIDS

\begin{tabular}{|c|c|c|c|c|}
\hline & Total sample $(n=4182)$ & $\begin{array}{l}\text { Personally knows someone who } \\
\text { died of AIDS ( } n=1743 \text { ) }\end{array}$ & $\begin{array}{l}\text { Does not personally know } \\
\text { someone who died of AIDS } \\
\text { ( } \mathrm{n}=2439 \text { ) }\end{array}$ & p Value \\
\hline \multicolumn{5}{|l|}{ Non-specific psychological distress } \\
\hline Medium & 10.3 & 12.6 & 8.7 & \\
\hline High & 7.8 & 9.1 & 6.9 & \\
\hline Low-medium-high & 91.6 & 90.1 & 92.6 & \\
\hline Any disorder & 16.8 & 20.8 & 13.6 & $<0.001$ \\
\hline Any depressive disorder & 5.5 & 6.5 & 4.8 & 0.020 \\
\hline Major depressive disorder & 4.3 & 5.7 & 4.9 & 0.039 \\
\hline Minor depressive disorder & 0.5 & 0.8 & 0.6 & 0.218 \\
\hline Any anxiety disorder & 8.7 & 10.8 & 7.1 & $<0.001$ \\
\hline Agoraphobia & 5.2 & 6.2 & 4.5 & 0.008 \\
\hline Any substance-related disorder & 5.7 & 8.1 & 4.0 & $<0.001$ \\
\hline Alcohol dependence/abuse & 4.9 & 6.7 & 3.6 & 0.002 \\
\hline Drug dependence/abuse & 1.5 & 2.5 & 0.7 & 0.001 \\
\hline
\end{tabular}

All cells are percentages (\%).

*Pearson's chi-squared p value comparing K-10 scores from low-medium-high vs very high, 0.018 .

Most of the crude associations persisted after adjustment for individual demographic characteristics and markers of socioeconomic status (panel B). However a number of associations were substantially weakened when adjusted for previous HIV testing, traumatic life events and recent life events (panel C). In the final models, individuals who knew someone who died of HIV/AIDS had $43 \%$ higher odds of any 12-month DSM-IV disorder, including $37 \%$ higher odds of any anxiety disorder and $89 \%$ higher odds of any substance-related disorder. Individual disorders significantly associated with knowing someone who died of HIV/AIDS included generalised anxiety disorder (OR 1.72; 95\% CI 1.05 to 2.82), social phobia (OR 1.02; 95\% CI 1.02 to 2.98 ), alcohol dependence or abuse (OR 1.76; 95\% CI 1.15 to 2.69) and drug dependence or abuse (OR 2.92; 95\% CI 1.22 to 6.96). These associations were consistent across separate models stratified by participant sex, age category, race and HIV testing history (data not shown).

Using the adjusted estimates from the models in panel C from table 4, we examined the proportion of mental disorders that may be attributed to knowing someone who died of HIV/AIDS in the South African population generally (ie, populationattributable fractions). Overall, approximately $15 \%$ of 12 month DSM-IV disorders in the South African adult population may be attributable to knowing someone who died of HIV/ AIDS. Among specific disorders, we estimated that approximately $9 \%$ of depressive disorders, $14 \%$ of anxiety disorders and $27 \%$ of substance use disorders (including alcohol dependence or abuse) are linked to knowing someone who died of HIV/AIDS.

\section{DISCUSSION}

To our knowledge, this is the first study to examine the impact of AIDS-related mortality on mental health in a general population sample from sub-Saharan Africa, the region most heavily affected by the HIV/AIDS epidemic. The results demonstrate strong associations between personal knowledge of someone who died of HIV/AIDS and DSM-IV defined depression, anxiety and substance use disorders during the previous 12 months. The widespread extent of AIDS-related mortality in South Africa (42\% of participants knew someone who had died of HIV-related causes) means that a sizeable proportion of common mental disorders in the South African population may be attributable to factors associated with AIDSrelated mortality.

These findings should be interpreted in light of several limitations. The measure of knowing someone who died of HIV/AIDS was relatively crude, and there is no objective measure to confirm the cause of death. This could lead to an inflated association with mental disorders if individuals without a disorder were less likely to correctly report knowing someone who died of HIV/AIDS, or if individuals with a disorder were more likely to falsely report knowing someone who died of HIV/AIDS; neither possibility seems obviously plausible. More importantly, we did not have data available on participants' perceived stigmatisation of HIV/AIDS, although some of those fears about HIV may reflect stigma, which may act as a moderator of the putative association. There was also no information available on the nature of the relationship between the participant and the deceased individual, such as whether they lived in the same household, were intimate partners or a parent or child. With future research into this question, how the type of relationship influences this association will require investigation. When the death occurred may also prove to be an important covariate, as increasing media coverage surrounding the epidemic and the availability of effective treatment for HIV disease may be working to reduce levels of HIV-related stigma in South Africa and, in turn, we may expect the associations documented here to be attenuated for deaths that occurred more recently. While these findings come from a nationally representative sample of South African adults, how these associations can be generalised to other settings is unclear, and this question requires examination in samples both from other countries where HIV is prevalent and from countries where HIV is less common. In addition, repeated surveys of population mental health over time (which are not available in 
Table 4 Results of multiple logistic regression models of the association between mental disorders and knowing someone who died of HIV/AIDS, (A) unadjusted, (B) adjusted for participant demographic and socioeconomic characteristics and (C) adjusted for participant demographic and socioeconomic characteristics, life events and HIV testing history

\begin{tabular}{|c|c|c|c|}
\hline & $\begin{array}{l}\text { Panel A. Crude } \\
\text { association }\end{array}$ & $\begin{array}{l}\text { Panel B. Adjusted for } \\
\text { participant } \\
\text { demographic } \\
\text { characteristics only* }\end{array}$ & $\begin{array}{l}\text { Panel C. Adjusted for participant } \\
\text { demographic characteristics, recent } \\
\text { life events, lifetime traumatic events } \\
\text { and previous HIV testing* }\end{array}$ \\
\hline & OR (95\% Cl) & OR $(95 \% \mathrm{Cl})$ & OR $(95 \% \mathrm{Cl})$ \\
\hline $\begin{array}{l}\text { Very high levels of non-specific } \\
\text { psychological distress }\end{array}$ & 1.38 (1.06 to 1.81$)$ & 1.46 (1.12 to 1.92$)$ & $1.23(0.92$ to 1.62$)$ \\
\hline Any DSM-IV disorder & 1.63 (1.31 to 2.03$)$ & 1.64 (1.31 to 2.07$)$ & 1.43 (1.15 to 1.78$)$ \\
\hline Any depressive disorder & $1.38(1.05$ to 1.80$)$ & $1.41(1.08$ to 1.83$)$ & $1.24(0.95$ to 1.62$)$ \\
\hline Major depressive disorder & $1.33(1.01$ to 1.76$)$ & $1.36(1.03$ to 1.78$)$ & $1.17(0.89$ to 1.54$)$ \\
\hline Minor depressive disorder & $1.68(0.72$ to 3.92$)$ & $1.80(0.85$ to 3.79$)$ & $1.96(0.89$ to 4.33$)$ \\
\hline Any anxiety disorder & $1.58(1.24$ to 2.01$)$ & 1.56 (1.19 to 2.03$)$ & $1.37(1.08$ to 1.76$)$ \\
\hline Agoraphobia & $1.42(1.10$ to 1.85$)$ & 1.35 (1.02 to 1.80$)$ & $1.24(0.95$ to 1.61$)$ \\
\hline Generalised anxiety disorder & 1.85 (1.18 to 2.91$)$ & 2.06 (1.25 to 3.37$)$ & $1.72(1.05$ to 2.82$)$ \\
\hline Panic disorder & $1.50(0.64$ to 3.50$)$ & $1.62(0.63$ to 4.16$)$ & $1.36(0.53$ to 3.52$)$ \\
\hline Post-traumatic stress disorder & $1.31(0.52$ to 3.29$)$ & $1.62(0.54$ to 4.87$)$ & $1.26(0.44$ to 3.57$)$ \\
\hline Social phobia & $2.08(1.30$ to 3.33$)$ & 2.00 (1.17 to 3.42$)$ & 1.74 (1.02 to 2.98$)$ \\
\hline Any substance-related disorder & $2.12(1.42$ to 3.18$)$ & $2.14(1.40$ to 3.27$)$ & 1.89 (1.28 to 2.79$)$ \\
\hline Alcohol dependence/abuse & 1.93 (1.26 to 2.95$)$ & $1.98(1.26$ to 3.10$)$ & 1.76 (1.15 to 2.69$)$ \\
\hline Drug dependence/abuse & 3.70 (1.58 to 8.68$)$ & 3.27 (1.31 to 8.14$)$ & $2.92(1.22$ to 6.96$)$ \\
\hline
\end{tabular}

All results are presented as odds ratios (OR) with $95 \%$ confidence intervals (CI).

*Participant demographic characteristics included in these models were age categories, sex, race and location (rural or urban); measures of socioeconomic status included in these models were education categories, employment status, household income and household asset ownership.

South Africa and most other low- and middle-income countries) would be valuable to examine how this association may change over time with the changing scope of the HIV/AIDS epidemic and the widespread use of antiretroviral therapy.

\section{What is already known on this subject}

- Previous research has highlighted the impact of HIV/AIDS on the mental health of infected individuals, mainly in Europe and North America, showing that HIV infection is associated with increased incidence of common mental illnesses such as anxiety and depressive disorders.

- However, little is known about how HIV-related mortality may affect mental health in general populations; such an impact is particularly plausible in regions such as southern Africa where HIV/AIDS is prevalent and levels of HIV-related stigma are high.

\section{What this study adds}

- This cross-sectional study provides novel data suggesting that HIV-related mortality may be associated with increased prevalence of common mental disorders in South Africa.

- These associations appear to be independent of individual demographic characteristics, socioeconomic status and traumatic life experiences.

- This study points to the indirect effect of the HIV epidemic on population mental health. Mental health services to support the families of infected individuals are needed to help reduce the impact of AIDS-related mortality.
The associations documented here persisted after adjustment for individual demographic characteristics, different measures of socioeconomic status and life events experienced, both recent and lifetime. However, we cannot rule out some form of unmeasured confounding factor that is both correlated with knowing someone who died of HIV/AIDS and a cause of common mental disorders. In particular, being affected by AIDS-related mortality may serve as a marker for susceptibility to more general psychosocial distress that is not related to the HIV epidemic, and not captured by the life events measures employed here. Related to this, we found significant differences in life stressors and sociodemographic variables between individuals who did and did not know someone who died of HIV/AIDS. The real possibility of residual confounding is neglected in mental health epidemiology, as in the discipline more broadly. ${ }^{27}{ }^{28}$ Here, this phenomenon would make the true associations between mental disorders and knowing someone who died of HIV/AIDS (and population-attributable fractions) smaller than those observed here.

These data begin to shed light on the potential populationlevel impact that the HIV epidemic may have in heavily affected countries. The indirect impact of the HIV/AIDS epidemic on other areas of population health has been well documented, including women's reproductive health, sexually transmitted infections and other infectious diseases such as tuberculosis. ${ }^{29-31}$ And while the effects of mental disorders on the HIV/AIDS epidemic have been reviewed, ${ }^{32}$ the indirect impacts of HIV/ AIDS on mental health have received little attention to date. Following on from the evidence from children orphaned by HIV/AIDS and caregivers of infected individuals, these data suggest that AIDS-related mortality may contribute substantially to depression, anxiety and substance-related disorders among adults in South Africa. In turn, it is possible that efforts to reduce HIV-related mortality, through the prevention of new infections as well as the effective treatment of infected 
individuals, could have substantial "spin-off" benefits in reducing the burden of common mental disorders. These findings are also of value in contributing to the understanding of why the population prevalence of common mental disorders may vary between countries, as the scope of the HIV/AIDS epidemic and other medical disorders and the societal stigmatisation linked to it may be an important cofactor in shaping the distribution of mental disorders.

While there is increasing attention to the mental health service needs of HIV-infected individuals in sub-Saharan Africa, ${ }^{6}{ }_{33} 34$ these findings underline the need for mental healthcare among families of individuals living with and dying of HIV/AIDS. In a setting of high HIV prevalence such as South Africa, where a large portion of the population knows someone affected by HIV (an estimated $42 \%$ of adults in this sample), the scope of this need is substantial. Nonetheless, these results highlight the need for counselling and psychosocial support for the families of individuals affected by HIV, and may be useful in helping to focus limited resources for mental health services on this group.

In summary, this study suggests that knowing someone who died of AIDS-related causes is associated with common mental disorders among South African adults. Although further research is needed to investigate specific aspects of this preliminary result, these data highlight the potential indirect benefits of reducing AIDS-related mortality and the need for strengthened mental health services targeting those affected by the HIV/AIDS epidemic.

Acknowledgements: The South African Stress and Health Study was carried out in conjunction with the World Health Organization World Mental Health (WMH) Survey Initiative. We thank the WMH staff for assistance with instrumentation, fieldwork and data analysis. A complete list of WMH publications can be found at http://www.hcp. med.harvard.edu/wmh/.

Funding: Supported by the United States National Institute of Mental Health (R01MH070884), the John D and Catherine T MacArthur Foundation, the Pfizer Foundation, the US Public Health Service (R13-MH066849, R01-MH069864 and R01 DA016558), the Fogarty International Center (FIRCA R01-TW006481), the Pan American Health Organization, Eli Lilly and Company, Ortho-McNeil Pharmaceutical, Inc., GlaxoSmithKline and Bristol-Myers Squibb. The South Africa Stress and Health study was funded by grant R01-MH059575 from the National Institute of Mental Health and the National Institute of Drug Abuse with supplemental funding from the South African Department of Health and the University of Michigan. D Stein and S Seedat are also supported by the Medical Research Council of South Africa.

Competing interests: None declared.

Ethics approval: The survey protocol, including all recruitment, consent and field procedures, was approved by the Human Subjects Committees of the University of Michigan, Harvard Medical School, and by a single project assurance of compliance from the Medical University of South Africa that was approved by the National Institute of Mental Health (USA)

\section{REFERENCES}

1. UNAIDS. AIDS epidemic update: December 2007. UNAIDS/07.27E / JC1322E. Geneva: UNAIDS, 2007

2. Dorrington RE, Johnson LF, Bradshow D, et al. The demographic impact of HIVIAIDS in South Africa. National and provincial indicators for 2006. Cape Town: Centre for Actuarial Research, South African Medical Research Council and Actuarial Society of Southern Africa.

3. Parker $\mathbf{R}$, Aggleton P. HIV and AIDS-related stigma and discrimination: a conceptual framework and implications for action. Soc Sci Med 2003;57:13-24.

4. Patel V, Araya R, Chaterjee S, et al. Treatment and prevention of mental disorders in low-income and middle-income countries. Lancet 2007;370:991-1005.
5. Freeman MC, Patel V, Collins PY, et al. Integrating mental health in global initiatives for HIV/AIDS. Br J Psychiatry 2005;187:1-3.

6. Collins PY, Holman AR, Freeman MC, et al. What is the relevance of mental health to HIV/AIDS care and treatment programs in developing countries? A systematic review. AIDS 2006;20:1571-82.

7. Kelly JA. HIV risk reduction interventions for persons with severe mental illness. Clin Psychol Rev 1997:17:293-309.

8. Smit J, Myer L, Middelkoop K, et al. Mental health and sexual risk behaviours in a South African township: a community-based cross-sectional study. Public Health 2006; 120:534-42.

9. Ciesla JA, Roberts JE. Meta-analysis of the relationship between HIV infection and risk for depressive disorders. Am J Psychiatry 2001;158:725-30.

10. Bing EG, Burnam MA, Longshore D, et al. Psychiatric disorders and drug use among human immunodeficiency virus-infected adults in the United States. Arch Gen Psychiatry 2001:58:721-28.

11. Sewell MC, Kathy JG, Rabkin JG, et al. Anxiety syndromes and symptoms among men with AIDS: a longitudinal controlled study. Psychosomatics 2000;41:294-300.

12. Rabkin JG, Ferrando SJ, Jacobsberg, LB, et al. Prevalence of axis I disorders in an AIDS cohort: a cross-sectional, controlled study. Compr Psychiatry 1997;38:146-54.

13. Evans DL, Ten Have TR, Douglas SD, et al. Association of depression with viral load, CD8 T lymphocytes, and natural killer cells in women with HIV infection. Am J Psychiatry 2002;159:1752-59.

14. Boarts JM, Sledjeski EM, Bogart LM, et al. The differential impact of PTSD and depression on HIV disease markers and adherence to HAART in people living with AIDS. AIDS Behavior 2006;10:253-61.

15. Leserman J, Pence BW, Whetten $\mathrm{K}$, et al. Relation of lifetime trauma and depressive symptoms to mortality in HIV. Am J Psychiatry 2007;164:1707-13.

16. Sengendo J, Nambi J. The psychological effect of orphanhood: a study of orphans in Rakai district. Health Transit Rev 1997;7(Suppl):105-24.

17. Cluver L, Gardner F. The mental health of children orphaned by AIDS: a review of international and southern African research. J Child Adolescent Mental Health 2007:19:1-17.

18. Pirraglia PA, Bishop D, Herman DS, et al. Caregiver burden and depression among informal caregivers of HIV-infected individuals. J Gen Intern Med 2005;20:510-14.

19. Orner P. Psychosocial impacts on caregivers of people living with AIDS. AIDS Care 2006;18:236-40.

20. Williams DR, Herman A, Kessler RC, et al. The South Africa Stress and Health Study: rationale and design. Metab Brain Dis 2004;19:135-47.

21. Kessler RC, Ustün TB. The World Mental Health (WMH) Survey Initiative version of the World Health Organization (WHO) Composite International Diagnostic Interview (CIDI). Int J Methods Psychiatr Res 2004;13:93-121.

22. Andrew G, Peters L. The psychometric properties of the Composite International Diagnostic Interview. Soc Psychiatry Psychiatric Epidemiol 1998;33:80-88.

23. Haro JM, Arbabzadeh-Bouchez S, Brugha TS, et al. Concordance of the Composite International Diagnostic Interview version 3.0 (CIDI 3.0) with standardized clinical assessments in the WHO World Mental Health Surveys. Int J Methods Psychiatric Res 2006;15:167-80.

24. Williams DR, Herman A, Stein DJ, et al. Twelve-month mental disorders in South Africa: prevalence, service use and demographic correlates in the population-based South African Stress and Health Study. Psychol Med 2008;38:211-20.

25. Kessler RC, Andrews G, Colpe LJ, et al. Short screening scales to monitor population prevalences and trends in nonspecific psychological distress. Psychol Med 2002:32:959-76.

26. Kessler RC, Barker PR, Colpe LJ, et al. Screening for serious mental illness in the general population. Arch Gen Psychiatry 2003;60:184-89.

27. Maldonado G. Adjusting a relative-risk estimate for study imperfections. J Epidemiol Community Health 2008;62:655-63.

28. Susser ES, Schwartz S, Moraba A, et al. Psychiatric epidemiology: searching for the causes of mental disorders. New York: Oxford University Press, 2006

29. Fleming DT, Wasserheit JN. From epidemiological synergy to public health policy and practice: the contribution of other sexually transmitted diseases to sexual transmission of HIV infection. Sex Transm Infect 1999:75:3-17.

30. Maher D, Harries A, Getahun H. Tuberculosis and HIV interaction in sub-Saharan Africa: impact on patients and programmes; implications for policies. Trop Med Int Health 2005;10:734-42.

31. McIntyre J. Maternal health and HIV. Reprod Health Matters 2005;13:129-35.

32. Prince M, Patel V, Saxena S, et al. No health without mental health. Lancet 2007;370:859-77.

33. Olley BO, Seedat S, Stein DJ. Persistence of psychiatric disorders in a cohort of HIV/ AIDS patients in South Africa: a 6-month follow-up study. J Psychosom Res 2006;61:479-84.

34. Freeman $\mathbf{M}$, Nkomo N, Kafaar Z, et al. Factors associated with prevalence of mental disorder in people living with HIV/AIDS in South Africa. AIDS Care 2007;19:1201-9. 